\title{
REPLACEMENT ARTHROPLASTY OF THE ROTATOR CUFF DEFICIENT SHOULDER
}

MICHAEL LAURENCE

From Guy's Hospital, London

\begin{abstract}
The rotator cuff is often severely damaged in arthritis of the shoulder and there is no satisfactory technique for its repair. Patients with a ruptured cuff and an eroded glenohumeral joint may have intractable pain, and standard methods of joint replacement are then inappropriate.

A ball and socket prosthesis has been designed to replace the function of both the rotator cuff and the glenohumeral joint. Mechanical testing has shown that the scapular cup can be securely fixed.

The outcome in 71 shoulders operated upon since 1973 is reported.
\end{abstract}

Most of the concavity of the scapular socket of the shoulder joint is provided by the rotator cuff, a complex combination of the capsule and the tendons of the periscapular muscles. When there is extensive rupture of this cover, the humeral head tends to sublux upwards and 'cuff-tear arthropathy' results (Neer, Craig and Fukuda 1983). This is found in advanced rheumatoid disease, with radiographic signs of glenoid and humeral head erosion (Kessel 1986; Crossan 1991). Such a shoulder often causes continuous severe pain, but replacement arthroplasty presents particular problems of fixation of the components and stability of the joint, severe enough to cause Neer to set 'limited goals' for arthroplasty (Neer, Watson and Stanton 1982; Neer 1988). To meet these circumstances, a prosthetic socket has been devised which can be fixed to all three parts of the scapula - the acromion, the coracoid and the lower lip of the glenoid.

\section{MATERIALS AND METHODS}

The prosthesis. A modified polyethylene cup of the Letournel-Lagrange type (Francobal, Howmedica International) is used. It articulates with a stainless steel sphere, $25 \mathrm{~mm}$ in diameter mounted on a $12 \mathrm{~cm}$ stem (Corin Medical, Cirencester, England) (Fig. 1). The components are semi-constrained with a 'snap' fit.

Most of the forces that act across the shoulder in the

M. Laurence, FRCS, Consultant Orthopaedic Surgeon Guy's Hospital, St Thomas'Street, London SEI 9RT, England.

(C) 1991 British Editorial Society of Bone and Joint Surgery $0301-620 X / 91 / 6201 \$ 2.00$

J Bone Joint Surg [ Br] 1991 ; 73-B :916-9. neutral position are tangential to the glenoid in the long axis of the humerus (Perry 1988). In the absence of the rotator cuff, a socket is required to replace the superior capsule. Since the centre of rotation of the glenohumeral joint is opposite the glenoid fossa (Perry 1988), there is enough space below the acromion to accommodate a correctly centred polyethylene cup of external diameter $50 \mathrm{~mm}$. Such a cup can be supported at three sites, the acromion, the coracoid process and the residual inferior lip of the glenoid.

In experiments on cadaveric scapulae, screws were set into the acromion and coracoid, and the glenoid was prepared by excision of its upper two-thirds to allow
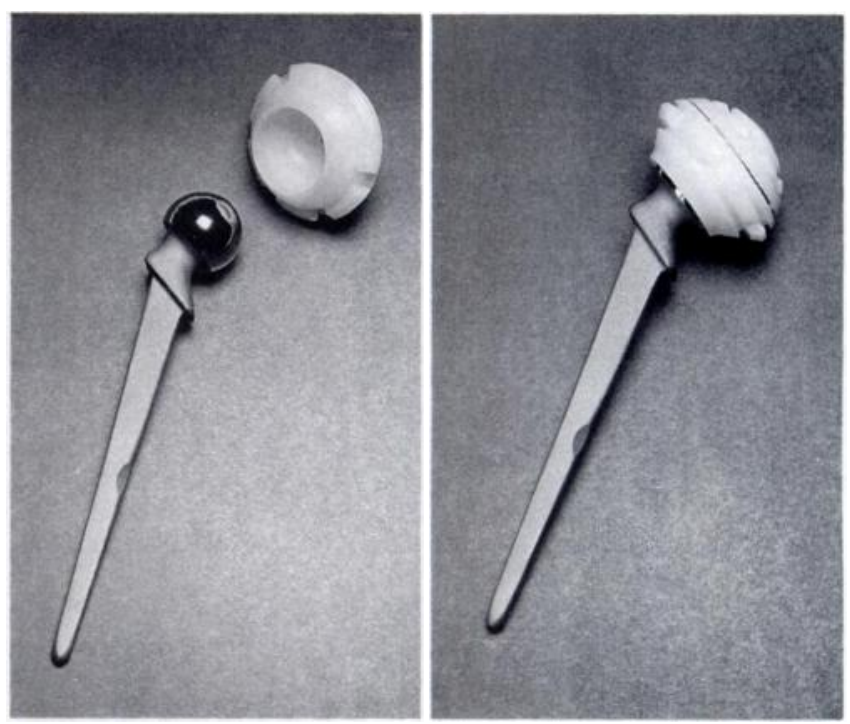

Fig. 1

The prosthesis 


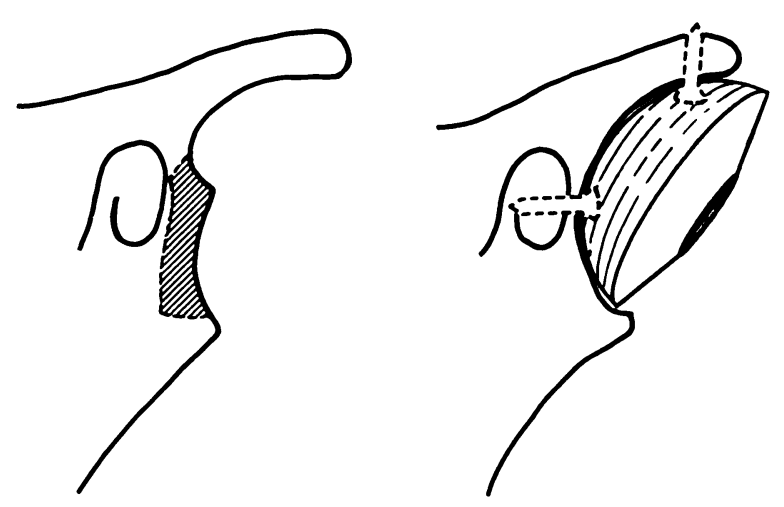

Fig. 2

Area of resection of the glenoid (hatched) and positions of screws to assist cement fixation of the scapular cup.

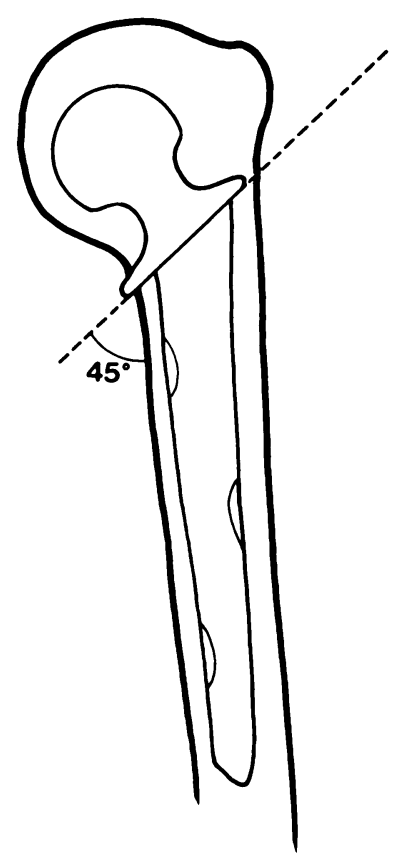

Fig. 3

Preparation of the humerus.

contact with its inferior lip (Fig. 2). A polyethylene socket was then fixed in position with methylmethacrylate cement. Load was then applied through a hook screwed into the cup. Compression, shear and pull-out loads in excess of $30 \mathrm{~kg}$ were sustained without failure, the hook itself failing at $35 \mathrm{~kg}$. This bears comparison with similar observations for other glenoid prostheses (Reeves et al 1974).

The position of the centre of rotation of the prosthetic joint was measured on 71 consecutive sets of postoperative radiographs. In seven cases it lay at the level of the centre of the original glenoid; in the other 64 the mean displacement was $3 \mathrm{~mm}$ upwards.

Surgical technique. Through a deltopectoral approach the surgical neck of the humerus is transected at $45^{\circ}$ to the long axis of the shaft (Fig. 3) and in a plane directed medially and slightly posteriorly to the epicondylar plane at the elbow.

The head is removed from the socket, often in a piecemeal fashion, taking with it remnants of diseased and damaged rotator cuff. The coraco-acromial ligament is excised, exposing bone on the under surface of the acromion and the lateral aspect of the coracoid process. The deep surface of the deltoid, which is often adherent, is dissected with care to avoid damage to the axillary nerve.

To make space for the cup, the upper two-thirds of the damaged glenoid is resected, using either a highspeed burr or a chisel and bone nibblers. Bone fragments are left around the cavity, in the expectation that they will eventually consolidate and provide additional support for the cup. Self-tapping screws are then placed into the coracoid and the acromion, and left protruding by about $4 \mathrm{~mm}$. A trial cup is inserted to ensure that the lower lip of the glenoid will provide the third point of fixation (Fig. 2). The medullary cavity of the upper humerus is curetted to receive the humeral component.

A small amount of methylmethacrylate cement is applied at each of the three scapular fixation points. The cup is then pushed into place taking care that no cement extrudes posteriorly where it could impinge on the deltoid and damage its nerve supply.

The humeral component is then cemented into position and the joint is snapped into reduction, from a position of slight extension. The arm is then moved through its range of flexion, extension and abduction. It is common to find that abduction is limited by contracture of the capsule inferiorly; this requires careful release, until $90^{\circ}$ is obtained.

After operation, the arm is suspended in $60^{\circ}$ abduction and $60^{\circ}$ flexion. On the second day, active assisted movement is started with hydrotherapy if available.

Patients. From 1973 to 1987 , a total of 71 arthroplasties were performed in 66 patients, 37 women and 29 men. Forty-five patients (34 women) had rheumatoid arthritis (four were bilateral cases), ten had degenerative arthritis, and seven post-traumatic arthritis. Two patients had suffered from avascular necrosis (one bilaterally), one from septic arthritis and one had neuropathic arthritis. The average age at the time of operation was 59 years (range 29 to 91 ).

\section{RESULTS}

Complications. There were no early deaths and no early postoperative complications. There were six late complications.

The single neuropathic joint dislocated and later both components became loose. In retrospect, this is regarded as an error of selection. 
Two patients had falls onto the operated arm at three and four years after surgery respectively. One of these fractured her radius and the other sustained a supracondylar fracture of the humerus. In both cases there was subsequent loosening of the humeral component. In another case, the humeral component became loose for no obvious cause, and was successfully recemented.

One shoulder became completely ankylosed by fibrous tissue, which recurred after complete surgical clearance two years after the initial arthroplasty. It remains stiff.

The last complication was seen in a woman with rheumatoid arthritis, who had her knee replaced at the same time as her shoulder. She dislocated her shoulder three weeks after the operations while trying to lift herself from a toilet seat with her shoulders hyperextended; open reduction was required.

Follow-up. The patients were reviewed between November 1988 and February 1990, by which time 11 had died from unrelated disease, and 19 had developed age-related conditions such as cerebrovascular accidents, heart failure, paralysis agitans or senile dementia which made detailed review of shoulder function impossible.

Only 36 patients with 38 arthroplasties were available for clinical review. For the remainder the status of the shoulder recorded in the last clinical note was included in the analysis with an appropriately reduced
Table I. Grading of results at a mean of 6.8 years (range 3 to 15)

\begin{tabular}{|c|c|c|c|c|c|c|}
\hline & \multicolumn{2}{|l|}{ Pain } & \multicolumn{2}{|c|}{ Movement } & \multicolumn{2}{|c|}{ Functional capacity } \\
\hline & Pre-op & Post-op & Pre-op & Post-op & Pre-op & Post-op \\
\hline 0 & 71 & 5 & 66 & 2 & 71 & 4 \\
\hline 1 & 0 & 9 & 5 & 41 & 0 & 11 \\
\hline 2 & 0 & 35 & 0 & 25 & 0 & 52 \\
\hline 3 & 0 & 22 & 0 & 3 & 0 & 4 \\
\hline
\end{tabular}

$0=$ severe pain $;$ no movement $;$ no functional use

$1=$ moderate pain; less than one-third range ; some functional use $2=$ slight pain; less than two-thirds range; moderate functional use $3=$ no pain; more than two-thirds range; good functional use
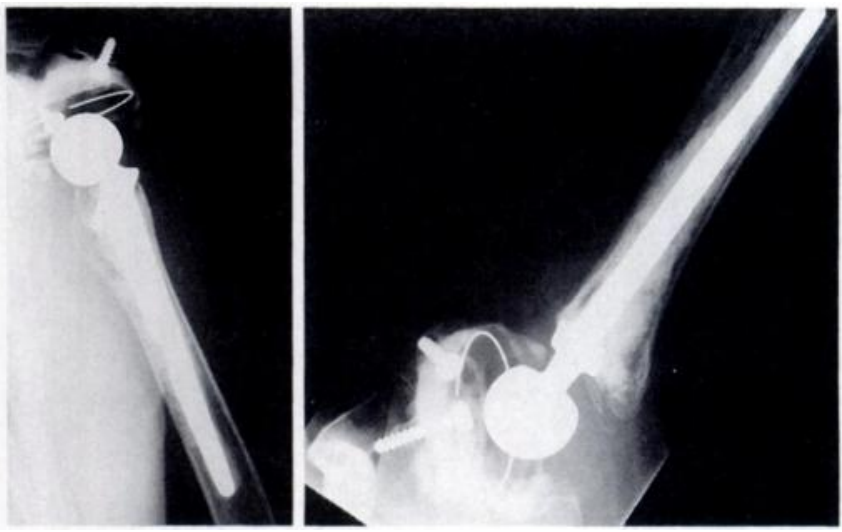

Fig. 4

Radiographs in adduction and abduction to show the extent of true glenohumeral movement.
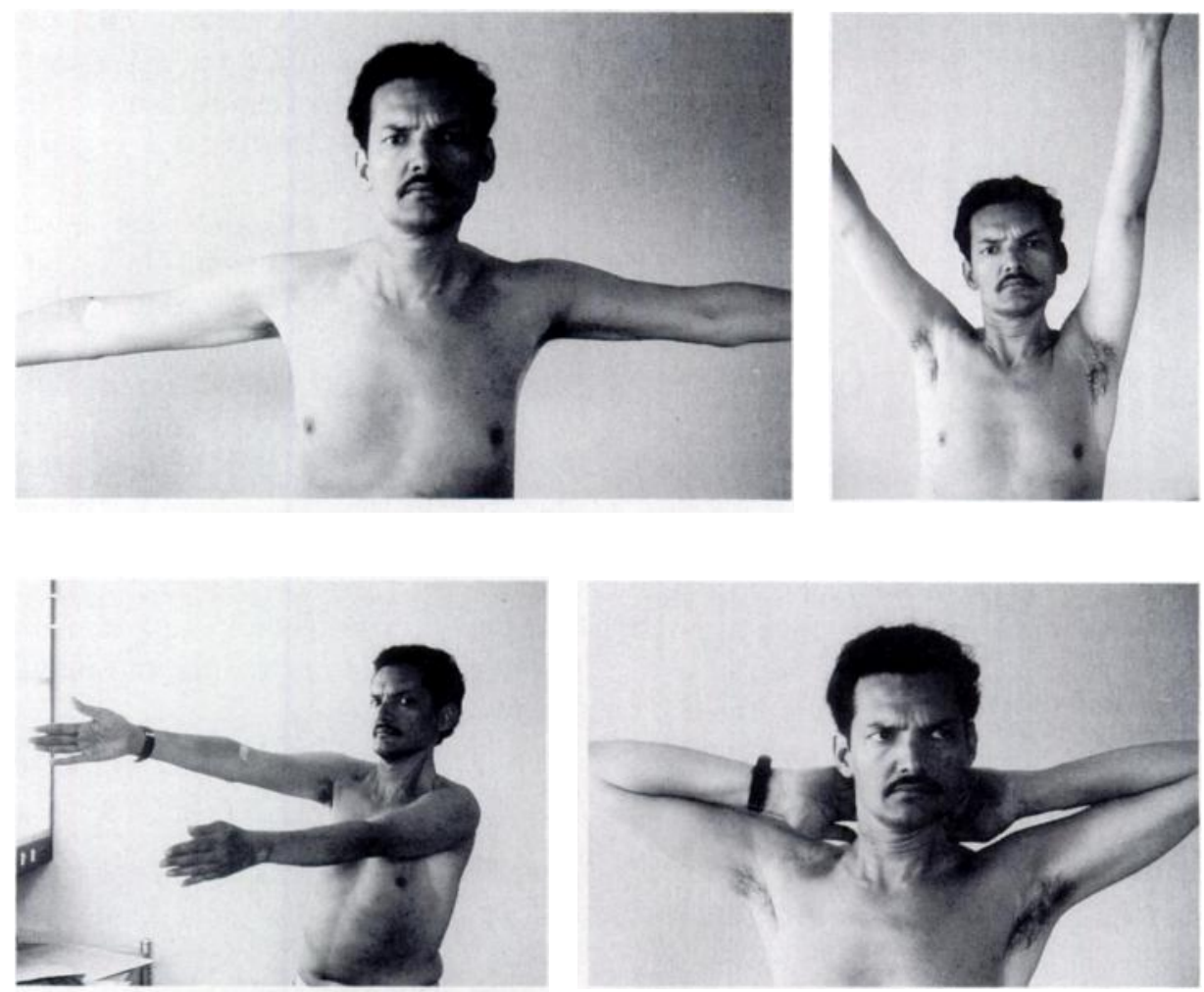

Fig. 5

Range of movement in a patient two years after arthroplasty of the right shoulder. 
follow-up time. Using this method the mean follow-up time was 6.8 years (range 3 to 15 ).

The clinical results were graded from 0 to 3 (see Table I).

Before operation all patients were in severe pain and none had any active glenohumeral movement. Eight

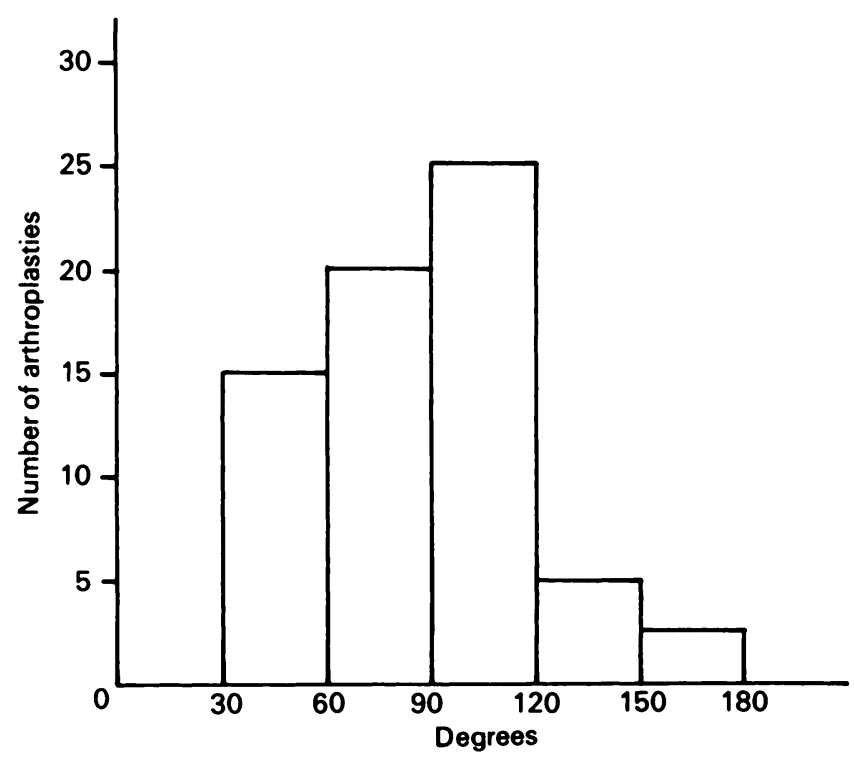

Fig. 6

Range of active abduction in slight flexion; the sum of glenohumeral and scapulothoracic movement $\left(90^{\circ}=\right.$ horizontal $)$.

patients, including those with avascular necrosis, neuropathy and post-traumatic arthritis, had passive ranges of rotation of up to $30^{\circ}$ and of flexion between $30^{\circ}$ and $90^{\circ}$.

Postoperatively, pain relief was complete in 22 of the 71 shoulders; 35 had caused some minor discomfort. Nine others had improved, but still had some pain. Two operations failed (neuropathy and ankylosis); three required revision surgery for loosening, two after trauma.

The range of movement after operation varied widely from almost normal (Figs 4 and 5) to ankylosis. The ranges of total shoulder abduction are given in Figure 6 . The mean ranges, with the true glenohumeral range in parentheses, were: abduction, $76^{\circ}\left(40^{\circ}\right)$; flexion, $81^{\circ}\left(40^{\circ}\right)$; rotation, $38^{\circ}\left(38^{\circ}\right)$; extension, $25^{\circ}\left(25^{\circ}\right)$.

Active use of the arm was regained by 56 of the patients and 26 were able to return to gainful employment. Eleven patients had to use elbow crutches because of disability in the lower limbs; none complained of difficulty in using these appliances.

\section{DISCUSSION}

The results of these arthroplasties are comparable with those of other designs of prosthesis (Coughlin, Morris and West 1979; Lettin, Copeland and Scales 1982; Post and Jablon 1983; Thornhill et al 1983; Norris 1991), despite the absence of the rotator cuff in all cases. The glenoid cup, which replaces the absent rotator cuff, has been shown to be secure by mechanical testing, and has loosened only in the patient with a neuropathic joint.

It was surprising that most patients gained some control of rotation, in spite of the lack of the short rotator muscles. It seems that their function is replaced by differential contraction of parts of the deltoid; this is visible beneath the skin in some thin patients. The range of active movement achieved by some younger patients without generalised disease (Fig. 5), illustrates the potential for functional recovery and calls into question the need to set limited goals for arthroplasty when the rotator cuff has been destroyed.

No benefits in any form have been received or will be received from a commercial party related directly or indirectly to the subject of this article.

\section{REFERENCES}

Coughlin MJ, Morris JM, West WF. The semiconstrained total shoulder arthroplasty. J Bone Joint Surg [ Am] 1979; 61-A:574-81.

Crossan JF. Pathology of the rheumatoid shoulder. In: Watson $\mathbf{M}$, ed. Surgical disorders of the shoulder. Edinburgh, etc: Churchill Livingstone, 1991:195-202.

Kessel L. A colour atlas of rupture of the rotator cuff London, etc: Wolfe Medical Publications, 1986:32.

Lettin AWF, Copeland S, Scales JT. The Stanmore total shoulder replacement. J Bone Joint Surg [Br] 1982; 64-B:47-51.

Neer CS. Non-constrained shoulder arthroplasty. In: Galasko CSB, Noble J, eds. Current trends in orthopaedic surgery. Manchester: Manchester University Press, 1988:16-22.

Neer CS II, Watson KC, Stanton FJ. Recent experience in total shoulder replacement. J Bone Joint Surg [Am] 1982; 64-A :319-37.
Neer CS, Craig EV, Fukuda H. Cuff-tear arthropathy. J Bone Joint Surg [Am] 1983; 65-A : 1232-44.

Norris TR. Unconstrained prosthetic shoulder replacement. In: Watson $\mathrm{M}$, ed. Surgical disorders of the shoulder. Edinburgh, etc: Churchill Livingstone, 1991 :504-5.

Perry J. Biomechanics of the shoulder. In: Rowe CR, ed. The shoulder New York, etc: Churchill Livingstone, 1988:5.

Post M, Jablon M. Constrained total shoulder arthroplasty: long-term follow-up observations. Clin Orthop 1983; 173:109-16.

Reeves B, Jobbins B, Dowson D, Wright V. Develpment of a total shoulder endoprosthesis. Human locomotor engineering. London: Institute of Mechanical Engineering, 1974.

Thornhill TS, Karr MJ, Averill RM, et al. Total shoulder arthroplasty: the Brigham experience. Orthop Trans 1983; 7:497. 